\title{
Activity and analysis of costs in a dedicated weaning centre
}

\author{
E.M. Clini1,2, P. Siddu², L. Trianni2, R. Graziosi², \\ E. Crisafulli2, M.T. Nobile2
}

ABSTRACT: Activity and analysis of costs in a dedicated weaning centre. E.M. Clini, P. Siddu, L. Trianni, R. Graziosi, E. Crisafulli, M.T. Nobile.

Aim. To analyse the diagnosis-related characteristics and the costs of treating patients with difficult/prolonged weaning from mechanical ventilation we have undertaken a retrospective observational study.

Methods. The study has considered all the patients admitted to our weaning unit of a regional Rehabilitation department during 3 consecutive periods since the opening date. Characteristics of the admitted patients and the DRG-related cares delivered have been recorded. A cost analysis has been obtained over time.

Results. The number of beds allocated to this unit (from 4 in the $1^{\text {st }}$ period to 6 in the $2^{\text {nd }}$ and $3^{\text {rd }}$ periods) and the number of patients cared for (from 32 to 43 and to 65 , respectively) increased over time. In particular, the COPD to non-COPD patient ratio (from 2.2 to 1.3 and to 1.0 ) and the DRG/patient weight (from $3.0 \pm 0.3$ to $3.1 \pm 0.2$ and to $3.3 \pm 0.2$ point $)$ changed significantly $(p<0.05)$. The daily reimbursement per patient from the public health care system only slightly increased, whereas the operating margin (reimbursement less costs) per patient significantly improved (from -304 , to +17 and $+55 € / p t / d a y$, respectively, $p<0.05)$ due to a gradual restriction in the variable costs. Length of stay, mortality rate and weaning rate did not change over time.

Conclusion. The weaning centre is a hospital area where economic burdens should be carefully evaluated. Given the actual reimbursement received on a national level for these patients, variable costs might be better spread, thus optimising the burdens without losing out on clinical outcomes.

Monaldi Arch Chest Dis 2008; 69: 2, 55-58.

Keywords: Weaning, Cost analysis, Intensive care.

${ }^{1}$ Institute of Respiratory Diseases, University of Modena-Reggio Emilia and 2 Villa Pineta Hospital - Dept. of Pulmonary Rehabilitation, Pavullo (MO), Italy.

Correspondence: Prof. Enrico Clini, Dpt. Oncology, Haematology and Pneumology, University of Modena, Ospedale Villa Pineta, Via Gaiato 127, 41026 Pavullon/F (MO), Italy; e-mail: enrico.clini@unimore.it

\section{Introduction}

Among the hospital acute care facilities, respiratory intensive care unit (RICU) has been growing in interest over recent decades $[1,2]$. Interestingly, the weaning process has been implemented and viewed as a very peculiar activity in this area $[3,4]$.

In Europe [5] as well as in our country [6] there is still a very low utilisation of RICU in areas that admit patients with prolonged or difficult weaning [7], thus leading to over usage of the more expensive beds in the intensive care units (ICUs).

Despite the fact that RICU has been shown to be a clinically effective [8] and cost-saving [9] alternative to a traditional ICU in caring for the critically ill respiratory patients, no previous studies have yet described the cost balance in a RICU specifically dedicated to weaning.

We have therefore undertaken this retrospective observational study to assess both the characteristics of patients admitted to a dedicated weaning centre and the changes to the economic analysis over time.

\section{Methods}

\section{The weaning unit}

Medical and administrative records of all the patients admitted to our regional weaning centre (RICU) during 3 consecutive periods (1st period: 2000 to 2001; $2^{\text {nd }}$ period: 2002 to 2003; 3rd period: 2004 to 2005) since the opening date have been reviewed from the hospital database. This RICU is part of a rehabilitation department inside a Private Hospital (Ospedale Villa Pineta, PavulloMO). Healthcare personnel (physicians, nurses and physiotherapists) is exclusively allocated to this unit; the ratio of physician, nurse, and physiotherapist-to-patient per day have been reported in the respective periods.

\section{Patients}

Patients who are cared for in the weaning unit have all been previously tracheostomised to facilitate the recovery from mechanical ventilation: the tracheostomy had been performed at the ICUs from which patients were then transferred. Upon 
admission to our unit, patients have been under mechanical ventilation for a period longer than 21 consecutive days.

The generated diagnosis-related-group categories (DRGs) and their relative weight in the study population, was based on the procedures carried out according to the ICD9-CM classification system [10]. Additional clinical data (length of stay) and outcomes (in-hospital mortality and success rate of the weaning process) have been also recorded.

\section{Costs}

The economic analysis of the cost of the RICU has been performed in accordance with methods usually related to the management control process [11] and to full cost accounting [12]. The RICU has been considered as a single cost centre.

Briefly, a formal balance analysis between charges (fixed and variable costs) and incomes (reimbursement) has been performed in the respective periods. The two main indices derived from the economic analysis were therefore the operating margin (reimbursement less total fixed and variable costs) and the operating profit (operating margin less costs due to several administrative charges, i.e. bank charges or administrative fees). Each cost is indicated in Euro (€) per patient/day.

The proportion of each component among the variable costs has been calculated over the respective periods.

\section{Statistics}

Statistics have been performed by means of a descriptive analysis including mean ( \pm SD) and/or percentage values of the considered variables. Comparison of data among the different periods has been performed using the Student $t$ test and/or the $\chi^{2}$ analysis with a significant level at the $p$ value below 0.05. A specific software package (SPSS 8.0 for Windows) has been used for all these purposes.

\section{Results}

Table 1 reports the main characteristics of the treated patients and their DRG-related features over the considered periods. The physician-to-patient ratio (1:3, 1:4 and 1:4 respectively) and the nurse-to-patient ratio $(1: 2,1: 2.5$ and $1: 3$ respectively) changed over the 3 periods, whereas the physiotherapist-to-patient ratio (1:6) remained unchanged. The number of beds allocated to RICU increased from 4 (in the 1 st period) to 6 (in the other subsequent periods).

The number of treated patients (from 32 to 43 and to 65 , respectively) increased accordingly (see table 1). Patients with an underlying diagnosis of COPD accounted by 68,55 and $50 \%$ of the total amount of the patients in the 3 periods respectively; therefore, patients with different underlying diagnosis with higher complexity (neuromuscular diseases, post-stroke, post-surgical and post-hypoxic states) increased at the same time. Nonetheless, the length of stay did not significantly change over time, despite the fact that different ranges of stay were recorded during the 3 periods (see table 1 ).

DRG 475 was the most represented (77\%) among the DRG categories, with a similar percentage across the periods (complete data set not showed). It should be noted that the DRG/patient mean weight significantly increased $(p<0.05)$ over time (see table 1).

Overall, length of stay, mortality rate (from 12 to 16 and to $18 \%$ ) and success rate of weaning (from 62 to 64 and to 59\%) did not change across the periods.

The economic analysis in the 3 periods has been reported in table 2 . The income (reimbursement) from the local health system only slightly increased (from $387 € / \mathrm{pt} /$ day in 1 st and 2 nd period to $418 € / \mathrm{pt} /$ day in the $3^{\text {rd }}$ period), whereas the operating margin significantly and completely reversed (from -304 , to +17 and $+55 € / p t / d a y$, respectively, $p<0.05)$ over time. In particular, this change has been generated by a restriction of the variable costs (mainly personnel) and to a different allocation of these resources in a larger setting (in-

Table 1. - Description of the treated patients and the DRG-related cares delivered over the respective periods

\begin{tabular}{|c|c|c|c|c|c|c|}
\hline Period & $\begin{array}{l}\text { Pts } \\
(\mathrm{nr})\end{array}$ & $\begin{array}{c}\text { Beds } \\
(\mathbf{n r})\end{array}$ & $\begin{array}{l}\text { COPD } \\
(\mathrm{nr}-\%)\end{array}$ & $\begin{array}{l}\text { Non-COPD } \\
(\mathrm{nr}-\%)\end{array}$ & $\begin{array}{c}\mathrm{DRG} / \mathrm{pt} \\
\text { weight }\end{array}$ & $\begin{array}{c}\text { Stay for care/pt (days) } \\
\text { [range] }\end{array}$ \\
\hline $1^{\text {st }}(2000-01)$ & 32 & 4 & $22-68$ & $10-32^{\wedge}$ & $3.0 \pm 0.3$ & $\begin{array}{l}41 \pm 10 \\
{[12-66]}\end{array}$ \\
\hline $2^{\text {nd }}(2002-03)$ & 43 & 6 & $24-55$ & $19-45^{\wedge}$ & $3.1 \pm 0.2$ & $\begin{array}{l}66 \pm 22 \\
{[3-128]}\end{array}$ \\
\hline $3^{\text {rd }}(2004-05)$ & 65 & 6 & $33-50$ & $32-50$ & $3.3 \pm 0.2 *$ & $\begin{array}{l}41 \pm 8 \\
{[7-55]}\end{array}$ \\
\hline
\end{tabular}


Table 2. - Description of costs in the weaning unit over the considered periods. Each cost value is indicated in Euro (€) per patient/day

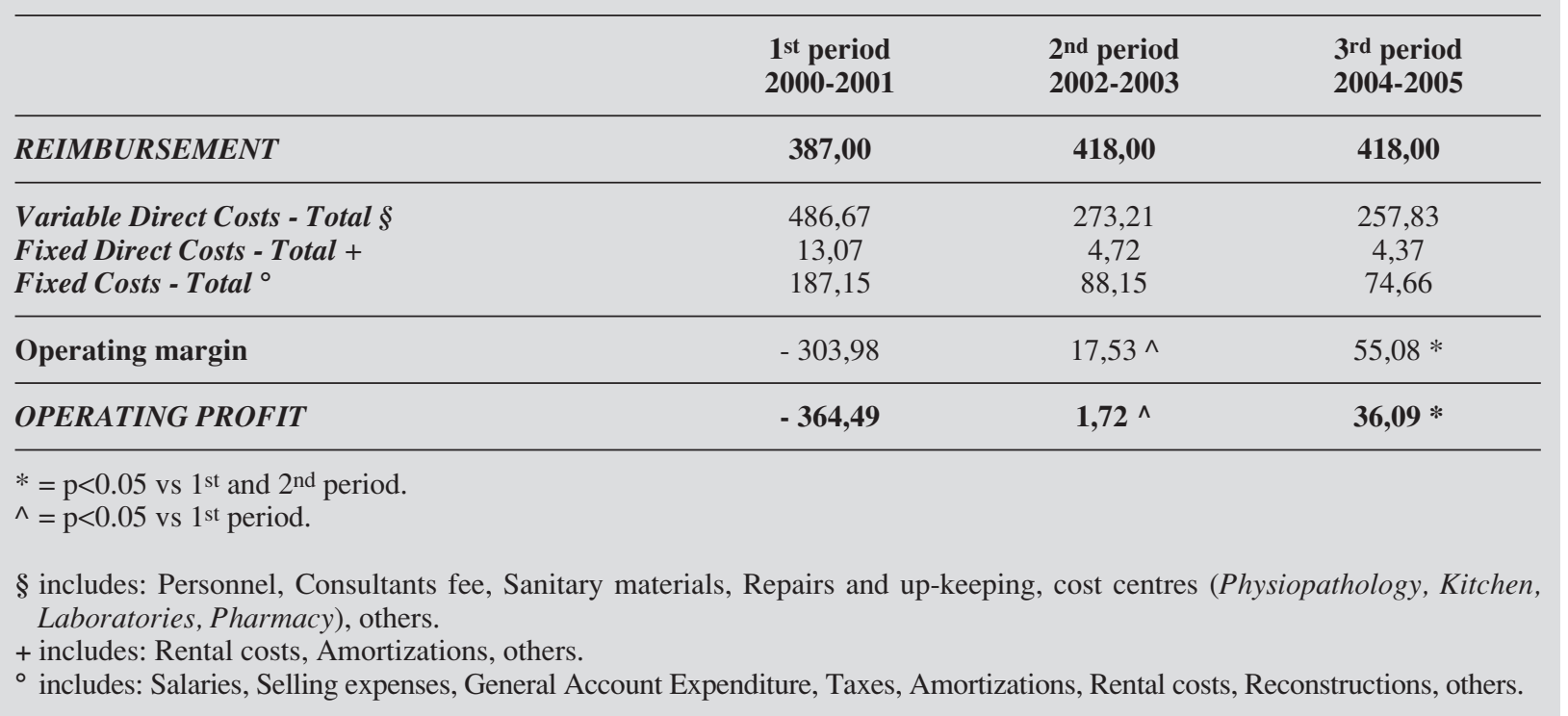

creased beds). Indeed, the cost of the allocated personnel accounted for 82,75 and $68 \%$ of the overall direct costs in the consecutive periods.

As a consequence, the gross operating profit changed accordingly (see in table 2), being that the administrative costs (see Methods for definition) did not significantly differ over time.

\section{Discussion}

This study shows that the dedicated weaning centre is a specialised area where severe patients with the need to undergo important procedures and heavy cost burdens are incurred are cared for. Given the constant amount of the income from the local health system and the increase in complexity and composition of the admitted patients, charges have been improved over time with decision-based restrictions on the variable costs in particular. These were not associated with worsen clinical outcomes.

Activity in RICU has a very important care burden, aimed at patients suffering from respiratory failure who are monitored and mainly treated by non-invasive ventilation, less frequently requiring assistance due to tracheostomy $[6,13]$.

RGs according to the ICD9-CM classification are likely to underestimate the patient's weight in the Italian RICUs [14]. It is also important to note that, in over 756 patients, the highly complex and costly DRGs (namely 475 and 483) were presented in only $21 \%$ of the whole population [14].

Our study is the first to describe the DRGs generated in a specifically dedicated regional weaning unit for tracheostomised and mechanically ventilated individuals. DRG 475 (which means full day ventilatory assistance through tracheostomy) has been represented in the large majority of patients in our unit, thus underlying the high cost and complexity of the clinical opera- tions in this area. Indeed, the DRG-generated weight/patient in our study was higher compared with the Italian RICU not specifically dedicated to weaning [14].

The mean age, and the main clinical outcomes in our study population were similar to those previously obtained in weaning units in the US [4, 15]. Despite the progressive increase in complexity of the DRGs (see table 1), these outcomes did not change over time. Underlying diagnosis of patients in a weaning unit is quite different from that of patients admitted in non-dedicated RICUs, where a very high percentage of COPD, with less than $20 \%$ of them suffering from two or more concomitant diseases, are cared for [9]. In our weaning unit the composition (COPD and non-COPD patients) gradually changed across the study periods: post surgical patients (about 29\%) and those with neurological sequaele (about 28\%) were the most represented diagnostic categories among the non-COPD patients.

To the best of our knowledge, this is the first study aimed at analysing the balance of cost in a weaning centre. One previous study [4] in a similar unit demonstrated that both mean charges and costs of patients under the weaning process (including costs of all allied health-care services) were lower during the first three days of admission than those occurring during the last three days spent in the ICU in which they have been previously managed, thus demonstrating a cost saving of more than $\$ 10,000$ per patient.

Our study has considered the economic analysis in this typical unit, showing that balancing costs with reimbursement may be difficult especially when starting this activity.

The main new finding in our study appears to be the restriction of the variable costs over time, personnel in particular (see table 2). The restriction of variable cost such as laboratories, procedures, drugs has been shown to characterise step- 
down units treating COPD patients, in particular [9]. Although it is rather difficult to compare our study with the multicenter study [9], it seems of interest that, as shown by our observation, the ongoing evaluation of total costs might enable the hospital administration to consider a different cost policy, given a similar amount of daily reimbursement per patient. Indeed, in the $2^{\text {nd }}$ and $3^{\text {rd }}$ period in our unit, a different number of allocated beds and a careful restriction of the variable direct costs (down to $68 \%$ of personnel charges due to their different allocation) produced a more favourable cost balance, thus making this activity as useful as (potentially) productive. Nonetheless, the profit may appear a least important objective for a hospital in which costs of beds in a critical care area are usually covered by the overall incomes covering the other health care activities. Indeed, previous reports from Europe [16] and US [3, 17-19] have shown significantly high costs and use of human resources in these critical care (although step-down) units. The problem of costs is very difficult to approach and many different items are crucial to quantify and therefore to subsequently assess the amount of reimbursement necessary. No specific guidelines or minimum levels of care have been proposed for patients admitted to these units; therefore, it is very difficult to compare costs and reimbursement globally.

The careful allocation of beds in these units may be important: indeed, it has been shown that the policy of reducing beds dedicated to weaning has determined a prolonged stay in the unit and, above all, significantly increased the waiting list and time before admission, thus increasing the superfluous time spent in the high costly ICUs [20].

Apart from the economic analysis we have also reported the main clinical outcomes in the 3 periods of observation. Length of stay, mortality rate and success rate of weaning did not change across the periods (see also Results section). However, as a potential limitation of this study we were not able to retrospectively assess changes in other clinical outcomes related to the patients' care (i.e. physiotherapy outcomes, nursing workload, etc.) which may have been potentially influenced by restriction of the variable direct cost, personnel in particular.

To conclude, the weaning centre is an area where patients with a critical balance of operating costs are cared for. It is likely that, given a constant amount of the income due to the actual reimbursement received on a national level, costs may be spread thus optimising the economic burden without losing out on too many of the major outcomes. Further studies should be addressed to better clarify this aspects.

Nevertheless, this kind of analysis might be helpful in performing a provisional budget and in addressing an adequate policy of requests for reimbursement from the local healthcare system.

\section{References}

1. Elpern EH, Silver MR, Rosen RL, Bone RC. The non invasive respiratory care unit. Pattern of use and financial implication. Chest 1991; 99: 205-208.

2. Byrick RJ, Mazer D, Caskennette GM. Closure of an intermediade care unit: impact on critical care utilizazion. Chest 1993; 104: 876-871.

3. Sheinhorn DJ, Artinian BP, Catlin JL. Weaning from prolonged mechanical ventilation: the experience at a regional weaning center. Chest 1994; 105: 534-539.

4. Dasgupta A, Rice R, Masha E, Litaker D, Stoller JK. Four-year experience with a unit for long-term ventilation (RSCU) at the Cleveland Clinic Foundation. Chest 1999; 116: 447-455.

5. Corrado A, Roussos C, Ambrosino N, et al. Respiratory intermediate care units: a European survey. Eur Respir J 2002; 20: 1343-1350.

6. Confalonieri M, Gorini M, Ambrosino N, Mollica C, Corrado A, on behalf of Respiratory Intensive Care Unit Group of AIPO. Respiratory Intensive Care Units in Italy: a national census and prospective cohort study. Thorax 2001; 56: 373-378.

7. Lemaire F. Difficult weaning. Intensive Care Med 1993; 19: 69s-73s.

8. Nava S, Rubini F, Zanotti E, et al. Survival end prediction of successful ventilator weaning and COPD patients requiring mechanical ventilation for more than 21 days. Eur Respir J 1994; 7: 1645-1652.

9. Bertolini G, Confalonieri M, Rossi C, Rossi G, Simini B, Gorini M, for the GiViTi and AIPO groups. Costs of the COPD. Differences between intensive care unit and respiratory intermediate care unit. Respir Med 2005; 99: 894-900.

10. International Classification of Diseases - $9^{\text {th }}$ revision. Office Edition Practice Management Information Corporation (PMIC), Los Angeles-CA, USA. 1997.

11. Anthony RN, Govindarajan V. Management control systems. Mc Graw-Hill / Irwin, New York, USA. 2004; DOI:10.1036/0072819316

12. Anthony RN, Young DW. Management control in nonprofit organizations. Mc Graw-Hill / Irwin, New York, USA. 2003; DOI:10.1036/0072508256

13. Nava S, Confalonieri M, Rampulla C. Intermediate respiratory intensive care units in Europe: a european perspective. Thorax 1998; 53: 798-802.

14. Potena A, Ballerin L, Putinati S, et al. Quality of generated Diagnosis related Groups in Italian Respiratory Intermediate Care Units. Monaldi Arch Chest Dis 2005; 61: 14-18.

15. Scheinhorn DJ, Chao DC, Stearn-Hassenpflug M, La Bree LD, Heltsley DJ. Post-ICU mechanical ventilation. Chest 1997; 111: 1654-1659.

16. Nava S, Evangelisti I, Rampulla C, et al. Human and financial costs of noninvasive mechanical ventilation in patients affected by COPD and acute respiratory failure. Chest 1997; 111: 1631-1638.

17. Bagley PH, Cooney E. A Community-based regional ventilator weaning unit. Development and outcomes. Chest 1997; 111: 1024-1029.

18. Engoren M. Marginal cost of liberating ventilator dependent patients after cardiac surgery in a stepdown unit. Ann Thorac Surg 2000; 70: 182-185.

19. Linsday ME, Bijwadia JS, Schauer WW, et al. Shifting care of chronic ventilator-dependent patients from the intensive care unit to nursing home. Joint Commission Journal on Quality and Safety 2004; 30: 257-265.

20. Vitacca M, Callegari G, Barbano L, Tramacere A, Clini E. Effects of restriction of beds dedicated to weaning on hospitals and health policy. Rass Patol App Respir 2004; 19: 141-147. 